\begin{tabular}{|c|c|c|}
\hline & Int.J.Curr.Microbiol.App.Sci (2016) 5(11): 774-781 & \\
\hline & International Journal of Current Microbiology and Applied Sciences & 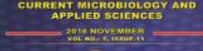 \\
\hline & ISSN: 2319-7706 Volume 5 Number 11 (2016) pp. 774-781 & \\
\hline $\begin{array}{l}\text { EXCELLENT } \\
\text { PUBLISHERS }\end{array}$ & & (1) \\
\hline
\end{tabular}

Original Research Article

http://dx.doi.org/10.20546/ijcmas.2016.511.089

\title{
In Vivo Studies comparing the Fever Patterns using Escherichia coli and Pseudomonas aeruginosa as Pyrogens in Rabbits
}

\author{
Hissah Al-Turki ${ }^{1}$, Samirah Al-Ali ${ }^{1}$, Reem Al-Khaldi ${ }^{1}$, Muneerah Al-Rowaila ${ }^{1}$, \\ and Lorina Badger-Emeka ${ }^{2} *$ \\ ${ }^{1}$ College of Medicine, King Faisal University, Al-Ahsa, Saudi Arabia \\ ${ }^{2}$ Department of Biomedical Sciences, College of Medicine, King Faisal University, \\ Al-Ahsa, Saudi Arabia \\ *Corresponding author
}

\begin{tabular}{|c|c|}
\hline & A B S T R A C T \\
\hline & \multirow{7}{*}{$\begin{array}{l}\text { The pyrogenic effects of microbial products have taken great attention of } \\
\text { researchers due to its usefulness in pharmaceutical industries for the monitoring of } \\
\text { adverse effects of contaminated drugs, intravenous fluids and vaccines. Fever } \\
\text { pattern caused by bacterial pyrogens could also help as a guide during empiric } \\
\text { antibiotic treatment in this era of multi-antibiotic resistant bacteria. The present } \\
\text { research study seeks to evaluate the fever pattern amongst bacterial strains of some } \\
\text { species through pyrogenic effects in rabbits as well as comparing the fever patterns } \\
\text { between the different bacteria species. Gram-negative bacteria, Escherichia coli } \\
\text { (ATCC } 25922 \text { ), non-coded } E \text {. coli, Pseudomonas aeruginosa (ATCC } 27853 \text { ) and } \\
\text { non-coded } P \text {. aeruginosa were used for the investigations. Each rabbit was } \\
\text { intravenously inoculated via the ear vein with one strain of bacteria and } \\
\text { temperature was monitored rectally at } 15 \text { minutes intervals post bacteria exposure. } \\
\text { The obtained results showed that fever was ascertained in all the rabbits } \\
\text { irrespective of the bacteria strain. The maximum difference from initial starting } \\
\text { temperature of between, } 0.6^{\circ} \mathrm{C} \text { to } 0.9^{\circ} \mathrm{C} \text { was obtained. The results indicate } \\
\text { fluctuations in temperature readings and revealed a significant (P value< } 0.05 \text { ) } \\
\text { difference in the means of the temperature between non-coded } P \text {. aeruginosa and } \\
\text { coded } E \text {. coli. Also, some of the rabbits exhibited hyperthermia signs during the } \\
\text { experiment irrespective of the initial rabbit starting temperature nor the bacteria } \\
\text { strain or species. Fever pattern exhibited by the two different gram negative } \\
\text { organisms are seen to be bacteria species specific. }\end{array}$} \\
\hline & \\
\hline & \\
\hline & \\
\hline Article In & \\
\hline & \\
\hline & \\
\hline
\end{tabular}

\section{Introduction}

Bacterial infections in humans generally results in fever presentation. Fever is said to be a physiological disorder which leads to elevated temperature that is above the normal one (Lawrence et al., 1990; Axeloid et al., 2008; Barone, 2009 and Shalini et al., 2006). According to Anochie (2013), fever is a common symptom of many medical conditions, inclusive of infectious diseases. The condition could be caused by bacterial infections, as well as febrile states like those seen in hypothalamic lesions due to endogenous pyrogens. Some exogenous substances are known to evoke fever and the 
lipopolysaccharide (LPS) derived from the gram-negative bacteria, is one of the extensively studied exogenous pyrogen (Dinarello, 2004). Fever caused by different microbial organisms tend to exhibit certain fever patterns. It is thought that fever patterns, though not diagnostic, are capable of suggesting the causative organism. Hectic fevers with chills and sweats are suggestive of an abscess or pyrogenic infection. Some bacterial infections have been described to exhibit characteristic fever patterns (Dimie, 2011). Also, in malaria infections, the Plasmodium species causing the disease often show different fever patterns which are specific to the Plasmodium species causing the disease (Srinivas, 2015 and James, 1996). Also, for bacterial infections resulting in Typhoid fever (Joshi, 2001), tuberculosis (Cunha et al., 2009), bacterial infections of bacterial pneumonia (Muhe, 1998), Cholangitis infection caused by Borrelia recurrent, all exhibit fever patterns suggestive of the various organisms (Lawrence et al., 1990). To this effect, Dinarello (2004), reported that in exogenous pyrogens, bacterial products considered as a host-derived fever-producing substances, caused fever. He also suggested that since there where innumerable fever-producing microbial products, fever-producing exogenous pyrogens causing fever shouldn't be amalgamated to one specific trace. Thus, the pattern of causing fever in bacterial infection would be expected to be different for gram-negative and gram-positive bacteria. Most Gram negative bacteria are pyrogenic. Escherichia coli is a good example of pyrogen producing gramnegative bacteria because of its ability to induce fever as has been reported by researchers (Vangroenweghe et al., 2004). The $21^{\text {st }}$ century has witnessed an increase in bacterial infections that are evolving new techniques at resisting treatment as they seem to evolve new means of defenses against treatment. Human population continues to expand and this expansion is not synonymous with the availability of adequate diagnostic tools. Shalini et al., (2006) were of the view that it was imperative to initiate broad spectrum antibiotic treatment before the availability of culture results. They were also of the view that though empiric therapy was appropriate, there was lack of consensus as to which antibiotic or combination of antibiotics could be used for such treatment. There is however the guidelines by the infectious disease society of America fever and Neutropenia panel which recommends that empiric antibiotics be based on patient clinical conditions (Hughes et al., 2002). Though the pattern of fever cannot be used as confirmed diagnostic tool, there might be a possibility that this could be a helpful lead in the absence of an available functioning laboratory, in postulating the probable bacterial organism responsible for an infection. Knowledge on bacteria fever patterns might go a long way in empiric antibiotic treatments particularly in this era of difficult to treat multi-antibiotic resistant bacteria. The present investigation looks into comparing the fever pattern of Escherichia coli and Pseudomonas aeruginosa as pyrogens in rabbits. It is with a view that such information could be a guide in the absence of immediate laboratory diagnostic tools as well as helping out during empiric treatments.

\section{Materials and Methods}

\section{Bacteria strains and Preparation of Inoculum}

Gram negative bacteria, Escherichia coli (ATCC 25922), non-code E. coli, Pseudomonas aeruginosa (ATCC 27853) and non-coded $P$. aeruginosa were used for the study. They were obtained from the 
Microbiology laboratory of the college of medicine, King Faisal University. Pseudomonas aeruginosa was sub-cultured on blood agar while $E$. coli was sub-cultured on MacConkey agar. Bacterial inoculum was prepared in sterile $0.9 \%$ saline solution to an estimated bacterial load of 0.157 $\mathrm{ng} / \mathrm{ml}$.

\section{Experimental animal model}

Healthy adult and young rabbits weighing between $1 \mathrm{~kg}-3 \mathrm{~kg}$ were used for the study. They were obtained and housed at the animal house of the college of medicine, King Faisal University. They had been fed on rabbit diet and water in line with the university's ethical policy on animals. They were kept in separate well ventilated cages, in an area of uniform temperature $\left( \pm 2{ }^{\circ} \mathrm{C}\right)$ and allowed to acclimatize to the laboratory environment for 4 weeks before they were used for the experiment. During the research experiments, they were kept in wellventilated cages.

\section{Animal inoculation}

For animal inoculation, each rabbit was placed in a rabbit restrainer to prevent vigorous movement during bacterial inoculation. The rabbit's ear was wiped with medium alcohol swap to make the veins prominent as well as sterilizing the area. Using a $1 \mathrm{ml}$ syringe, $0.4 \mathrm{ml}$ of infecting bacteria suspension, was drawn out and injected into the rabbit through the ear veins. Post inoculation, pressure was applied at the injection site to prevent bleeding. The rabbits were then returned to their cages to acclimatize before temperature readings were taken.

\section{Animal Groupings}

All experiment was carried out in replicates. The rabbits from each group were labeled based on the type of bacteria they had been inoculated with. Thus in group A, the rabbits were inoculated with Escherichia coli (ATCC 25922), while the rabbits in group 2 were inoculated with non-code $E$. coli. Rabbits in the third group, were inoculated with Pseudomonas aeruginosa (ATCC 27853 ) while those in the $4^{\text {th }}$ group with noncoded $P$. aeruginosa.

The experiment was then repeated with another set of rabbits. And this replicate experiment was termed the group B animals. Control experiment consisted rabbits that had been inoculated with sterile saline.

\section{Temperature recording}

The initial temperature of each rabbit was taken before they were inoculated with bacteria. Post inoculation, temperature readings were rectally taken every 15 minutes for 3 hours. A digital thermometer was used to monitor temperature post bacterial inoculation. The thermometer was inserted into the rabbits' rectum to a depth of about $2.5 \mathrm{~cm}$. The digital thermometer remained inserted throughout the sensing period. A rabbit restrainer was used to keep the animals steady during temperature monitoring. A bleeping sound from the thermometer signified the maximum temperature at which the thermometer was removed.

\section{Statistical Analysis}

Results were analyzed using Excel 2013 and SPSS 19. Data are presented as mean \pm SD. Student T-test was used to compare the pair of experimental groups. While one- way ANOVA test was used to define levels of significance among groups. To confirm the significance between groups, Turkey honestly significant difference [HSD] posthoc test was used. Statistical significance was defined as $\mathrm{p}<0.05$ 


\section{Results and Discussion}

\section{Effect of exposure to Escherichia coli infection on the body temperature}

The results on the effect of blood inoculation of experimental rabbits with different strains of $E$. coli is shown in figure 1. For rabbits infected with ATCC $25922 E$. coli, temperature of $37.6^{\circ} \mathrm{C} 15$ minutes post exposure was seen to increase gradually peaking at 70 minutes into the experiment at a temperature of $38.7{ }^{\circ} \mathrm{C}$. Temperature is seen to remain stable for the next 30 minutes before declining until a temperature of about $37.8^{\circ} \mathrm{C}$ was reached 3 hours post initial exposure. For the non-coded E. coli, there was no specific pattern exhibited. With an initial starting temperature of $38.2^{\circ} \mathrm{C} \quad 15$ minutes post bacteria inoculation, a maximum temperature of $38.8^{\circ} \mathrm{C}$ was reached 75 minutes after exposure. A steep decrease was seen between $90-120$ minutes into the experiment, a slight rise 15 minutes later with no specific pattern of increase or decrease until the experiment was terminated.

\section{Effect of exposure to Pseudomonas aeruginosa infection on the body temperature}

The results on the effect of the different $P$. aeruginosa strains as pyrogens in Rabbits is shown in Figure 2. For the ATCC 27853 strain, the initial temperature of about $38^{\circ} \mathrm{C}$, was at 15 minutes post bacterial exposure. The temperature is seen to remain constant 30 minutes post infection after which there was a gradual increasing in temperature, peaking at about 70 minutes post infection. There was a gradual decrease in temperature as is shown in the figure 80 minutes post exposure until a stable temperature of $38^{\circ} \mathrm{C}$ was obtained 3 hours post exposure to the pyrogen. Observation for the non-coded $P$. aeruginosa was slightly different. The initial temperature of $37.6^{\circ} \mathrm{C} 15$ minutes post exposure, remained constant at 30 minutes post infection, with a slight decrease in temperature 15 minutes later. One hour into the investigation, there was a gradual increase in temperature, peaking an hour later at a maximum temperature of $38.2^{\circ} \mathrm{C}$, then decreasing gradually until a temperature of about $37.7^{\circ} \mathrm{C}$ was obtained one hour later.

\section{Comparison between Bacteria species}

The results on the statistical comparison in mean temperatures between bacteria species are presented in Tables 1 and 2. ATCC 27853 P. aeruginosa produce a similar rise in temperature as those in the replicate experiment. The result is validated by $\mathrm{p}$ value of 0.770 , showing that there is no statistical difference and the results are shown in table 1. For the non-coded $P$. aeruginosa, there was an observed difference in experiment 1 and the replicate with the difference being statistically significant (p-value 0.010). ATCC 25922 E. coli showed a similar pattern with p-value 0.026 . For the non-coded E. coli, there was no observed difference, the comparison was not statistically significant (p-value 0.219 ) and the results are as shown in table 1.

The results in table 2 showing the comparison in association in temperature rise between the different tests organisms. For ATCC 27853 P. aeruginosa, there is an association between rise in temperature and all the other test organisms as indicated by their p-values which are statistically significant. All the other test organisms exhibited a similar association in temperature rise with the exception the two strains of $E$. coli. These strains gave a pvalue of 0.999 , indicating a non-significant statistical difference. 


\section{Physical Observations during studies}

In between the $3^{\text {rd }}$ and $5^{\text {th }}$ temperature readings, the experimental rabbits exhibited distress during which they passed sticky white watery substance. It was not possible to ascertain if this was urine or feces. Also as the temperature increased in some rabbits to about $40{ }^{\circ} \mathrm{C}$ to $40.2{ }^{\circ} \mathrm{C}$, they were observed to shiver intensely with their hairs on end after which there was a drop in temperature. The results from the present investigation has shown the ability of different strains of bacteria pyrogens to cause fever in rabbits. All the groups of rabbits inoculated with the different bacteria strains were observed to have elevation of body temperature from the starting initial temperature. Anochie (2013) had reported that fever is generally agreed to be present if the elevated temperature is at or over $37.5-$ $38.3^{\circ} \mathrm{C}$.

Table.1 Showing the difference between experiments and their replicates inoculated with the same strain of the bacteria species

Organism Experiments T-test $\begin{gathered}\text { Degree of } \\ \text { freedom }\end{gathered}$

$\begin{array}{lllll}\text { Code P. aeruginosa } & \text { ex1-ex2 } & -.299 & 11 & \mathbf{. 7 7 0} \\ \text { P. aeruginosa } & \text { ex1-ex2 } & -3.080 & 11 & .010 \\ \text { Coded } \boldsymbol{E} . \text { coli } & \text { ex1-ex2 } & -2.572 & 11 & .026 \\ \text { E. coli } & \text { ex1-ex2 } & -1.303 & 11 & \mathbf{. 2 1 9}\end{array}$

Ex1 = experiment 1; ex2 = experiment 2.

Table.2 Showing the association between the different test Organisms in temperature rise

\begin{tabular}{|c|c|c|c|}
\hline Test organism & Comparison & Mean Difference & Sig. \\
\hline \multirow{3}{*}{ ATCC $P$. aeruginosa } & P. aeruginosa & $1.19167^{*}$ & .000 \\
\hline & ATCC E. coli & $.52083^{*}$ & .032 \\
\hline & E. coli & $.49583^{*}$ & .045 \\
\hline \multirow[t]{3}{*}{ P. aeruginosa } & ATCC $P$. aeruginosa & $-1.19167^{*}$ & .000 \\
\hline & ATCC E. coli & $-.67083^{*}$ & .003 \\
\hline & E. coli & $-.69583^{*}$ & .002 \\
\hline \multirow[t]{3}{*}{ ATCC E. coli } & ATCC $P$. aeruginosa & $-.52083^{*}$ & .032 \\
\hline & P. aeruginosa & $.67083^{*}$ & .003 \\
\hline & E. coli & -.02500 & .999 \\
\hline \multirow[t]{3}{*}{ E. coli } & ATCC $P$. aeruginosa & $-.49583^{*}$ & .045 \\
\hline & P. aeruginosa & $.69583^{*}$ & .002 \\
\hline & ATCC E. coli & .02500 & .999 \\
\hline
\end{tabular}


Fig.1 A comparison of the effect of coded and non-coded E. coli infection in inducing fever over time.

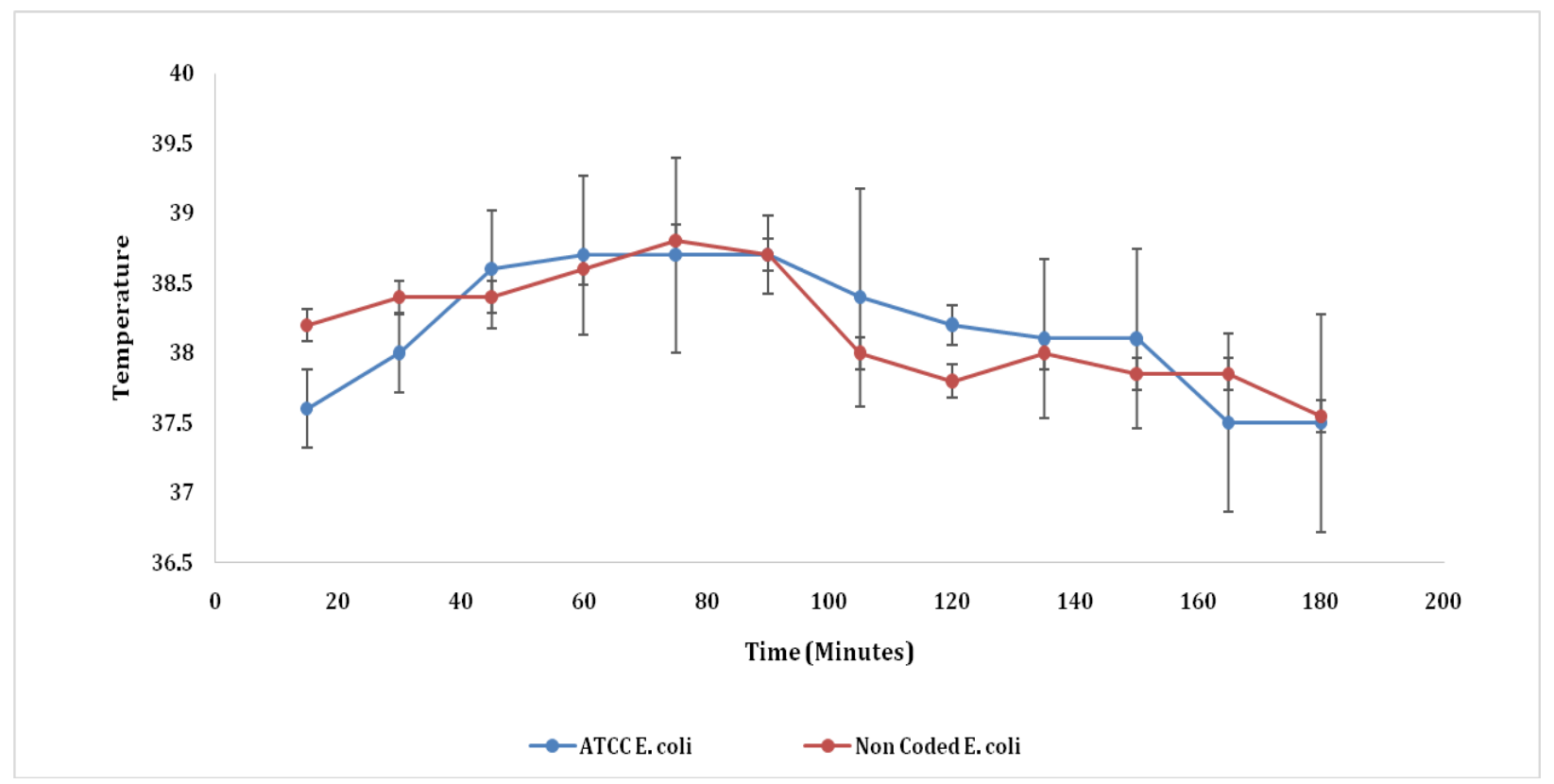

Fig.2 showing a comparison of the effect of coded and non-coded $P$. aeruginosa infection in inducing fever over time

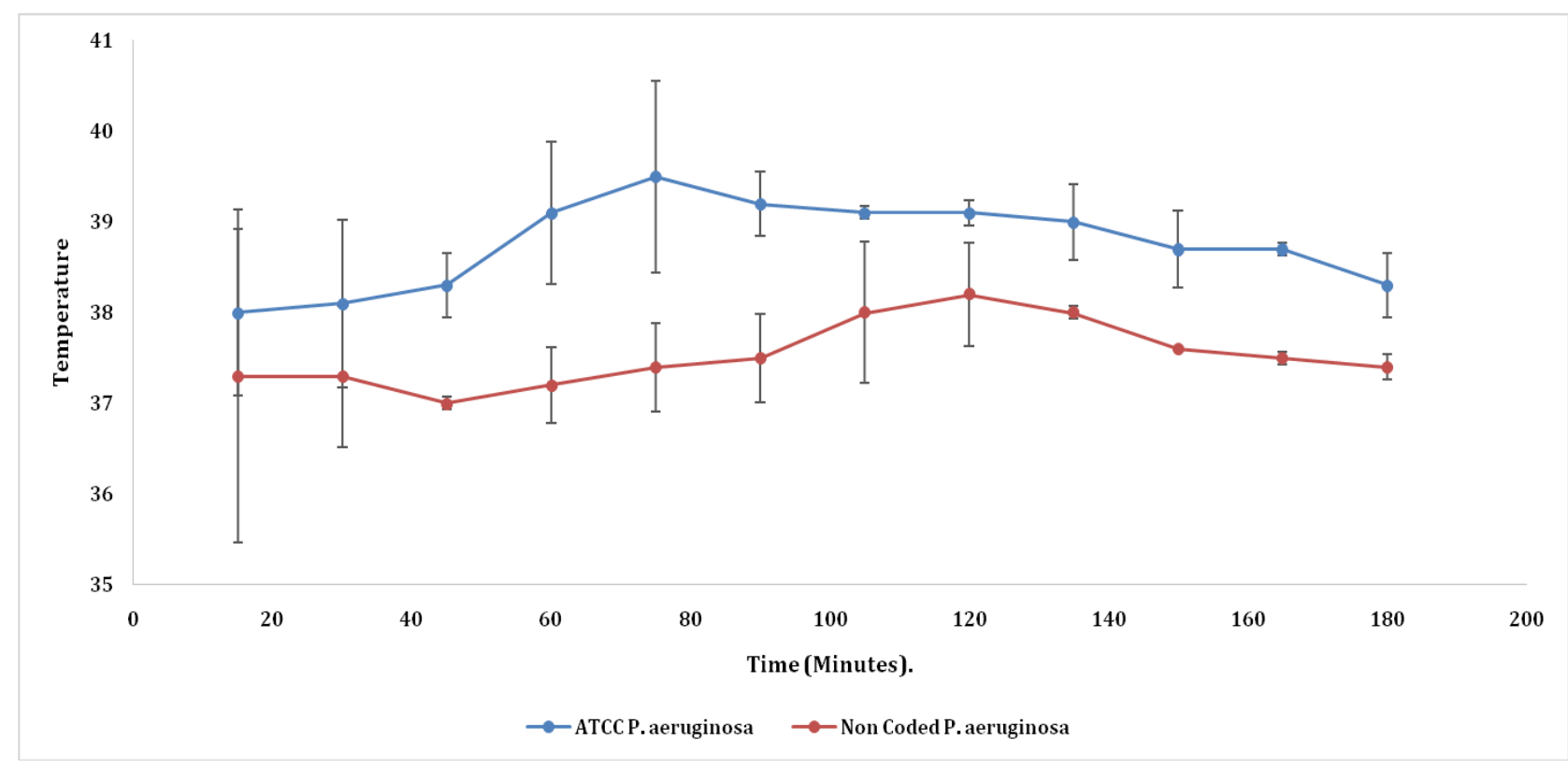

It can therefore be said that fever was ascertained by the two strains of bacteria under consideration. The present findings are similar to earlier report by Granowitz et al., (1993) as reported by Dinarello et al.,
(2004). They had reported febrile response in volunteer humans who had been injected with $3 \mathrm{ng} / \mathrm{kg}$ of $E$. coli LPS intravenously. Apart from all the subjects having developed fever, the pattern of fever exhibited by the 
subjects is similar to those shown in the present study by $E$. coli infected rabbits. This therefore indicates the possibility that the pattern of fever caused by different strains of Escherichia coli has not change over time as is also confirmed by the nonstatistically difference shown by the E. coli strains in the present investigation.

Also, the rabbits inoculated with E. coli, though there was elevation of initial body temperatures at various times post bacterial exposure, there was no specific pattern in the increase or decrease in temperatures until the termination of the experiment. No specific reason can be attributed to this. However there is a possibility of variation in the ability of the different rabbits to fight or resist infection due to different factors. These contributing factors could be age, gender, size/weight. Also, other contributing factors could have been the environmental and the animal breed. Anochie (2013) attributed normal body temperatures to vary depending on factors such as age, gender, time of the day, activity level among other factors. Though the rabbits used in the present study had been allowed to acclimatize to laboratory conditions before they were used for the study, environmental conditions cannot however be completely ruled out. The fever pattern exhibited by temperature rise in rabbits inoculated with the different strains of $P$. aeruginosa did exhibited specific defined patterns. This therefore suggest increased in temperature at regulatory set points as had been indicated by past researchers Karakitsos et al., 2008). This they said resulted in increased muscle tone leading to shivering. This therefore might explains the physical observation recorded in the present study. Some rabbits passed white watery waste, other passed frequent stool, while the rest shivered, followed by drop in body temperature. An increase in body temperature was seen to have resulted in shivering. Anochie (2013) and Shalini (2006) in describing the pathophysiology of a typical fever in humans commented that the patient shivers with the temperature is rising. The physical observations as seen in the present research are therefore in agreement to those of reactions resulting due to pyrexia.

In conclusion, the present study demonstrates that two different species, Gram-negative bacteria, Escherichia coli (ATCC 25922), non-coded E. coli as well as Pseudomonas aeruginosa (ATCC 27853) and non-coded $P$. aeruginosa had the ability to cause pyrexia in all the rabbits in different patterns that had been used for the research. Fever pattern exhibited by the two different gram negative organisms are bacteria species specific, thus indicating that although both of the bacteria pathogens are gram negatives, the fever patterns appeared to be organism define.

\section{Acknowledgement}

The researchers would like to acknowledge Mr. Hani Alfarhan for his technical assistance, Dr. Sayed Ibrahim Ali for his statistical impute. We also thank Dr. Sujatha Tejavat and Mrs. Muneerah Ibrahim AlOhaymid for their assistance.

\section{Conflict of Interest}

The authors declare none.

\section{References}

Anochie, P.I. 2013. Mechanisms of fever in humans. Int $\mathrm{J}$ Microbiol Immunol Res. Vol. 2, no. 5, pp 037-043. http://www.apexjournal.org.

Axelrod, Y.K., Diringer, M.N. 2008. Temperature management in acute 
neurologic disorders, Neurol. Clin., Vol. 26, no. 2, pp 585-603.

Barone, J.E. 2009. Fever: fact and fiction. $J$. Trauma, Vol. 67, no. 2, pp 406-9.

Cunha, B.A.1., Krakakis, J., McDermott, B.P. 2009. Fever of unknown origin (FUO) caused by military tuberculosis: diagnostic significance of morning temperature spikes. Heart and Lung. Vol. 38, no. 1, pp 77-82. doi: 10.1016/j.hrtlng.2008.03.002.

Dimie, O. 2011. Fever, fever patterns and diseases called 'fever' - A review. $J$. Infect. Public Health, Vol. 4, no. 3, pp 108-124.

Dinarello, C.A. 2004. Infection, fever, and exogenous and endogenous pyrogens: some concepts have changed. J. Endotox. Res., Vol. 10, no. 4, pp 201-222. DOI $10.1179 / 096805104225006129$

Dosogne, H.E., Meyer, A., Sturk, J. et al., 2002. Effect of enrofloxacin treatment on plasma endotoxin during bovine Escherichia coli mastitis. Inflammatory Res., Vol. 51, pp 201-205.

Granowitz, E.V., Porat, R., Mier, J.W., et al. 1993. Hematological and immunomodulatory effects of an interleukin-1 receptor antagonist coin fusion during low-dose endotoxemia in healthy humans. Blood, Vol 82, pp 2985-2990.
Hughes, W.T., Armstrong, D., Bodey, G.P., et al. 2002. guidelines for the use of antimicrobial agents in neutropenic patients with cancer. Clin. Infect. Dis., Vol. 34, pp 730-751.

James, M.C. 1996. Stephen LH. Malaria. Med. Microbiol., 4th edition.

Joshi, Y.K. 2001. Typhoid Fever, Clinical features. J. Indian Academy of Clin. Med., Vol. 2, no 1 \& 2, pp 21-4.

Karakitsos, D., Karabinis, A. 2008. Hypothermia therapy after traumatic brain injury in children. N. Engl. J. Med., Vol. 359, no. 11, pp 1179-80.

Lawrence, D., James. F.S. 1990. Fever, Chills, and Night Sweats. Clinical Methods: The History, Physical, and Laboratory Examinations. Chapter 211. 3rd edition.

Muhe, L. 1998. Pattern of resolution of tachypnoea and fever in childhood pneumonia. East Afr. Med. J., Vol. 75, no. 2, pp 63-7.

Shalini, D., Donna, S.Z. 2006. Pathophysiology and Management of Fever. J. Supportive Oncol., Vol. 4, no. 1 , pp $9-16$.

Srinivas. 2015. Malaria Fever. http://www.malariasite.com/

Vangroenweghe, F., Duchateau, L., Burvenich, C. 2004. Moderate Inflammatory Reaction during Experimental Escherichia coli Mastitis in Primiparous Cows. $J$. Dairy Sci., Vol. 87, pp 886-895.

\section{How to cite this article:}

Hissah Al-Turki, Samirah Al-Ali, Reem Al-Khaldi, Muneerah Al-Rowaila and Lorina BadgerEmeka. 2016. In Vivo Studies comparing the Fever Patterns using Escherichia coli and Pseudomonas aeruginosa as Pyrogens in Rabbits. Int.J.Curr.Microbiol.App.Sci. 5(11): 774781. doi: http://dx.doi.org/10.20546/ijcmas.2016.511.089 